\title{
Supporting Information for Proteomics in non-model organisms: a new analytical frontier
}

Michelle Heck ${ }^{1,2,3}$ and Benjamin A. Neely ${ }^{*}$

${ }^{1}$ Emerging Pests and Pathogens Research Unit, USDA Agricultural Research Service, Ithaca, NY, USA

2 Plant Pathology and Plant Microbe Biology Section, School of Integrative Plant Science, Cornell University, Ithaca, NY, USA

${ }^{3}$ Boyce Thompson Institute, Ithaca, NY, USA

${ }^{4}$ Chemical Sciences Division, National Institute of Standards and Technology, Charleston, SC, USA

Table of Contents

S-2 Supplementary Table S1 


\section{Supplementary Table S1. Specific NCBI taxon IDs and their designation for $\mathbf{2 3}$ mammal groups used in Figures 2 and 3. The number of genome assemblies on Genbank and genome annotations on RefSeq (valid as of 12 March, 2020) with published proteomic data sets on the Proteomics Identifications Database (PRIDE; as of 17 January 2020) are listed as well.}

\begin{tabular}{|c|c|c|c|c|}
\hline $\begin{array}{l}\text { taxon } \\
\text { ID }\end{array}$ & mammals & $\begin{array}{c}\text { proteomic } \\
\text { data sets }\end{array}$ & $\begin{array}{c}\text { genome } \\
\text { assemblies }\end{array}$ & $\begin{array}{c}\text { genome } \\
\text { annotations }\end{array}$ \\
\hline 91561 & even-toed ungulates & 32 & 120 & 26 \\
\hline 9989 & rodents & 28 & 93 & 25 \\
\hline 33554 & carnivores & 25 & 60 & 23 \\
\hline 9443 & primates & 20 & 63 & 28 \\
\hline 9787 & odd-toed ungulates & 11 & 12 & 4 \\
\hline 9979 & rabbits \& hares & 5 & 3 & 2 \\
\hline 948950 & anteaters and sloths & 5 & 5 & 0 \\
\hline 9397 & bats & 4 & 37 & 12 \\
\hline 9779 & elephants & 4 & 1 & 1 \\
\hline 38609 & Herbivorous marsupials & 3 & 3 & 2 \\
\hline 28734 & elephant shrews & 2 & 1 & 1 \\
\hline 9815 & aardvarks & 1 & 2 & 1 \\
\hline 9774 & manateees and dugongs & 1 & 1 & 1 \\
\hline 38608 & carnivorous marsupials & 1 & 2 & 1 \\
\hline 38605 & possums & 1 & 1 & 1 \\
\hline 948951 & armadillos & 1 & 3 & 1 \\
\hline 9255 & egg-laying mammals & 0 & 1 & 1 \\
\hline 9362 & insectivores & 0 & 8 & 3 \\
\hline 9389 & golden moles & 0 & 1 & 1 \\
\hline 9369 & tenrecs & 0 & 2 & 1 \\
\hline 30656 & flying lemurs & 0 & 1 & 1 \\
\hline 9392 & tree shrews & 0 & 3 & 1 \\
\hline 9971 & pangolins & 0 & 3 & 1 \\
\hline
\end{tabular}

